\title{
EFFECTS OF DIETARY FAT ON CHOLESTEROL METABOLISM: REGULATION OF PLASMA LDL CONCENTRATIONS
}

\author{
ANDREW M.SALTER ${ }^{1}$ AND DAVID A. WHITE \\ 1 Department of Applied Biochemistry and Food Science, University of Nottingham, \\ Sutton Bonington Campus, Loughborough, Leics LE12 5RD \\ 2 Department of Biochemistry, University of Nottingham Medical School, Queen's \\ Medical Centre, Nottingham NG7 2UH
}

\section{CONTENTS}

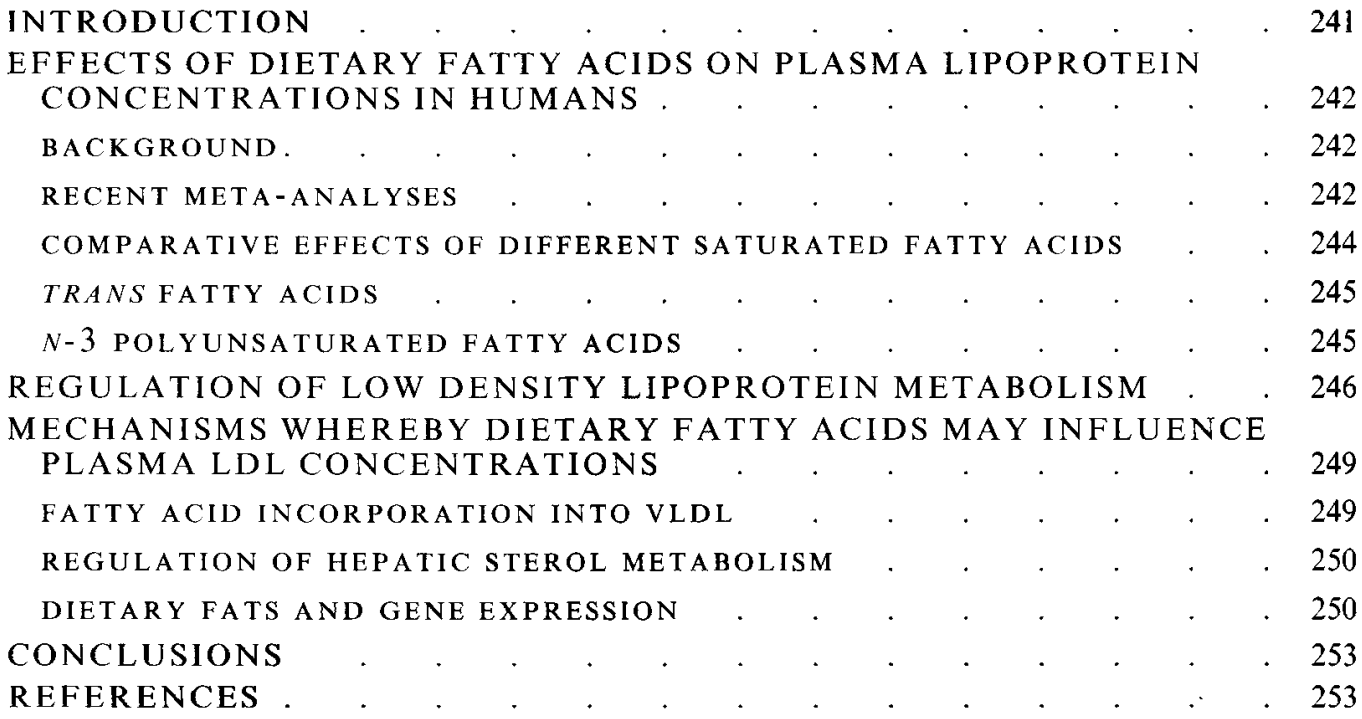

\section{INTRODUCTION}

The involvement of cholesterol in the atherosclerotic process has been recognized for over a century. A wealth of epidemiological data has almost indisputably shown that elevated plasma cholesterol concentrations are associated with increased risk of premature atherosclerosis and its clinical manifestations of coronary heart disease (CHD) and stroke. What has proved more difficult is the demonstration that reducing plasma cholesterol, particularly by dietary manipulation, reduces such risk.

This is further complicated by the suggestion that any potential benefit of cholesterol lowering in terms of reduced atherosclerosis is offset by an increase in death from other causes (Oliver, 1991). A good example of such studies is the Multiple Risk Factor Intervention Trial (1982). Cholesterol lowering by dietary changes, reduced blood pressure and cessation of smoking resulted in a modest decrease in mortality from cardiovascular disease but this was counteracted by an increase in death from other causes. One complication in this study was, as in many, that the control 'usual care' group also showed a reduction in risk factors resulting in only modest differences between the two groups. 
In recent years, however, our ability to reduce plasma cholesterol by pharmacological means has been dramatically improved with the introduction of the 'statins'. This group of compounds acts by inhibiting the activity of hydroxymethylglutaryl-CoA (HMG-CoA) reductase $(E C 1.1 .1 .88)$, particularly in the liver, thereby inhibiting cholesterol synthesis. The recent West of Scotland Heart Study (Shepherd et al. 1995) utilizing one such drug, Pravastatin, has provided the most conclusive evidence to date that lowering plasma cholesterol does reduce risk of CHD. A $20 \%$ reduction in plasma cholesterol was associated with a $30 \%$ reduction in CHD mortality and morbidity. No significant increase in death from other causes was seen. Thus it appears that if a big enough reduction in plasma cholesterol can be obtained then significant benefits can be achieved.

It is probably neither desirable nor economically feasible to put everyone with elevated plasma cholesterol on cholesterol lowering drugs. Thus, attention must return to dietary modification to achieve sufficient reductions in plasma cholesterol to reduce atherosclerotic risk. Most of today's dietary advice relates back to data collected by Ancel Keys in the 1960s (Keys et al. 1965). As such the main emphasis is on reducing saturated fatty acid (SFA) intake. The first part of this review looks at recent developments in human experimentation with particular emphasis on the effects of dietary fatty acids on individual plasma lipoprotein fractions. The second part focuses on recent developments in our understanding of the regulation of the expression of key genes involved in low density lipoprotein (LDL) metabolism and how they may be regulated by specific dietary fats.

\section{EFFECTS OF DIETARY FATTY ACIDS ON PLASMA LIPOPROTEIN CONCENTRATIONS IN HUMANS}

\section{BACKGROUND}

It is over 30 years since Keys et al. (1965) and, working independently, Hegsted et al. (1965) derived predictive equations to quantify the effects of dietary cholesterol and fat on plasma cholesterol concentrations. These equations were derived by regression analysis from a large number of human feeding trials in which the amounts of cholesterol and saturated and polyunsaturated fatty acids were manipulated.

While there are minor quantitative differences between the two equations, the overall conclusions were similar: (1) dietary cholesterol has a relatively modest plasma cholesterol raising effect; (2) dietary SFA have a potent plasma cholesterol raising effect; (3) dietary polyunsaturated fatty acids (PUFA) have a plasma cholesterol reducing effect; (4) the cholesterol raising effect of SFA is more potent than the cholesterol lowering effects of PUFA.

\section{RECENT META-ANALYSES}

Despite a vast number of human feeding studies since the derivation of these equations these major conclusions have withstood the test of time remarkably well. However, as our knowledge of the role of lipoproteins in the development of premature cardiovascular disease has increased it has become apparent that there is a need to distinguish effects of diet on LDL cholesterol from those on high density lipoprotein (HDL) cholesterol. Furthermore, increasing interest has focused on the effects of specific fatty acids rather than broad classes based on degree of saturation. As a result, in recent years a number of attempts have been made to develop predictive equations which take into account these factors. Three such studies have involved meta-analysis of existing data to derive equations describing the effect of dietary fatty acids on plasma total, LDL and HDL cholesterol (Mensink \& Katan, 1992, Hegsted et al. 1993; Yu et al. 1995). 
In terms of effects on total plasma cholesterol the results of these analyses tend to confirm the findings of Keys et al. (1965) and Hegsted et al. (1965). However, some controversy has arisen over the effects of monounsaturated fatty acids (MUFA), of which oleic acid is quantitatively the most important. Two groups (Mensink \& Katan, 1992; Yu et al. 1995) suggested a small hypocholesterolaemic effect but Hegsted et al. (1993) confirmed their earlier results which showed MUFA to be neutral and hence equivalent to carbohydrate. These conflicting views were addressed in another recent meta-analysis (Gardner \& Kraemer, 1995) which looked specifically at studies where MUFA and PUFA were directly exchanged without significant changes in total and saturated fat or dietary cholesterol. Fourteen such studies, performed between 1983 and 1994, were identified. The overall conclusion of this analysis was that there was no significant difference between the effects of MUFA and PUFA on total, LDL or HDL cholesterol but that PUFA produced a modest reduction in plasma triacylglycerol (TAG). It was suggested that the disagreement between this study and those of Keys et al. (1965) and Hegsted et al. (1965) with regard to the relative effects of MUFA and PUFA may be related to the type of feeding study considered. While these previous studies looked at dietary manipulation where significant changes in total and saturated fat and dietary cholesterol occurred, this report limited itself to those in which all of these variables were kept constant and only MUFA and PUFA were interchanged.

In terms of the effects on individual lipoprotein fractions, all of the analyses show that SFA increase both LDL and HDL cholesterol but that the effect on the former is substantially greater. Thus, most of the effects of SFA on total plasma cholesterol can be attributed to increases in the LDL fraction. The equations suggest that PUFA decreases LDL but slightly increases HDL. These data contradict certain reports that suggest PUFA may actually reduce HDL cholesterol (Mattson \& Grundy, 1985). It has been suggested that such an effect only occurs at very high PUFA concentrations which would not normally occur in the human diet ( $\mathrm{Yu}$ et al. 1995).

Again, controversy exists on the effects of MUFA on individual lipoprotein fractions, with Hegsted et al. (1993) claiming no effect on LDL concentrations but Mensink \& Katan (1992) and Yu et al. (1995) suggesting an LDL lowering effect of a lower magnitude than PUFA. All agree that MUFA raise HDL cholesterol by about the same amount as PUFA.

Perhaps the most ambitious of these attempts to quantify the effects of dietary fatty acids on plasma lipoprotein concentrations was that of $\mathbf{Y u}$ et al. (1995). These authors used 18 published studies to perform meta-analysis on the effects of individual fatty acids on plasma total, LDL and HDL cholesterol in men and women. One of the major differences between this and previous analyses is that it includes stearic acid (C18:0) which in the past has tended to be included with other saturates or regarded as neutral. The latter was confirmed in the present study where no correlation coefficient for stearic acid was significantly different from zero. Generally, the predictive changes for total and LDL cholesterol were similar for men and women; however, interesting sex differences were seen in the response of HDL cholesterol. The responses to stearic acid and PUFA were significantly different between the sexes with both significantly reducing HDL cholesterol in women compared with men.

As with the Keys and Hegsted equations, quantitative differences exist in the recent studies described above. Furthermore, disagreement still prevails over the effects of MUFA. However, again some common conclusions can be drawn: (1) saturated fats increase LDL and HDL cholesterol but have a greater effect on LDL; (2) MUFA and PUFA probably both decrease LDL cholesterol; (3) except at extremely high intakes, PUFA do not decrease HDL and MUFA may increase it; (4) the study of Yu et al. (1995) indicates that stearic acid has an essentially neutral effect on total plasma cholesterol and 
LDL and may lower HDL in females; (5) there is little evidence to suggest that moderate changes in total fat intake without a change in fatty acid composition have any beneficial effects on total cholesterol, and they might produce a more detrimental lipoprotein profile.

There is one major dissenting voice against the major conclusions from these studies. Hayes and co-workers have over a number of years published findings in a number of species, including primates and humans, which suggest that palmitic acid, the major saturate in the human diet, may not be hypercholesterolaemic (Hayes et al. 1991; Hayes \& Khosla, 1992; Khosla \& Hayes, 1993; Sundram et al. 1994, 1995; Hayes et al. 1995). Furthermore, they suggest that the cholesterol lowering effect of PUFA is not linear and at increasing concentrations PUFA become less effective. Re-analysing a subset of the data of Hegsted et al. (1965), they derived an equation which attributes all of the modulating effect of dietary fat on plasma cholesterol to myristic acid (C14:0) and linoleic acid (C18:2) (Hayes \& Khosla, 1992). This relationship appears to hold for individuals consuming low or normal amounts of dietary cholesterol. When intakes exceed $500 \mathrm{mg} / \mathrm{d}$ then palmitic acid may contribute to the elevation in plasma cholesterol. Another factor highlighted by Hayes et al. (1995) is that studies where dietary fatty acids are fed as synthetic fats may not give the same results as when they are present within naturally occurring fats and oils and that this has led to misinterpretation of data. While it is well established that TAG structure can have important effects on various aspects of lipoprotein metabolism (Small, 1991), recent evidence casts doubt on whether this is a major factor in regulating the 'cholesterolaemic' properties of SFA. We looked at two fats rich in dioleoylmonopalmitoylglycerol where the palmitic acid was esterified to either the central (OPO) or outer (POO) carbon atoms of the glycerol. While we found a number of differences in chylomicron metabolism with the two fats, no overall effect was seen on total, LDL or HDL cholesterol in hamsters (Pufal et al. 1995). Similar results have recently been reported for the same fat blends in humans (Zock et al. 1994).

\section{COMPARATIVE EFFECTS OF DIFFERENT SATURATED FATTY ACIDS}

So, under normal conditions is palmitic acid really 'neutral' or equivalent to oleic acid, as suggested by Hayes and coworkers? Hegsted et al. (1965) originally reported myristic acid to be four times more hypercholesterolaemic than palmitic acid. The recent meta-analyses by Mensink \& Katan (1992) and Yu et al. (1995) appear to support this finding. By contrast, lauric and palmitic acids appear to be equally potent.

Not all human feeding trials support these results from meta-analysis. Combining the results of two feeding trials, Derr et al. (1993) derived an equation which indicated that myristic acid and palmitic acid were at least equal in their cholesterol raising properties, which agreed well with the original Keys equation. Dietary fats used in this study were from natural sources and included olive oil, cocoa butter, soyabean oil, butter, chocolate and a mixture of cocoa butter and butter $(4: 1 \mathrm{mix})$. A study utilizing a myristic acid-rich synthetic fat with a palm oil-rich fat blend showed myristic acid to be about 1.5 times as cholesterol raising as palmitic acid (Zock et al. 1994). Another study comparing similar fats showed little difference in the effects of the two fats on total plasma cholesterol and suggested that myristic acid might even be beneficial as it significantly increased HDL cholesterol (Tholstrup et al. 1994). Of course, the results of these latter two experiments may be influenced by the fact that they used synthetic rather than natural fats (Hayes et al. 1995). At the present time it would seem prudent to regard $\mathrm{C} 12: 0, \mathrm{C} 14: 0$ and $\mathrm{C} 16: 0$ as potentially hypercholesterolaemic, at least until further evidence is available. 


\section{$T R A N S$ FATTY ACIDS}

Fatty acids containing double bonds in the trans as opposed to the cis configuration occur rarely in nature (see also the review by Gurr in this volume). The action of bacteria in the rumen creates some such fatty acids which then can accumulate in the tissues and milk of ruminant animals. However, the major source of trans fatty acids is processed oils and fats, such as magarines produced by chemical hydrogenation of vegetable and fish oils. Such foods can contain appreciable amounts of trans $\mathrm{C} 18: 1$ (elaidic acid) and lesser amounts of a range of PUFA containing various combinations of $c i$ s and trans double bonds. Concerns over the potential effects of such fatty acids have been voiced over a number of years though earlier data were judged to be inconclusive. However, data emerging from the recent American Nurses Study (Willett et al. 1993) have renewed such concern. The study amassed dietary histories from 85095 subjects and suggested a stronger link between CHD and trans fatty acid consumption than with SFA intake. This is supported by a case-control study by Ascherio et al. (1994) which compared the trans fatty acid intake of patients with a first acute myocardial infarction with control subjects. After adjustment for age, sex and energy intake, intake of trans fatty acids showed a direct correlation with risk of myocardial infarction. This relationship remained highly significant even after adjustment for established coronary risk factors and dietary intakes of other fatty acids and antioxidant vitamins.

Unfortunately insufficient data are available to perform meta-analysis on trans fatty acid intake of a similar manner to that performed on other types of fatty acid. However, the results of recent well controlled human feeding studies do support the idea that the increased risk of CHD described above may be the result of increased LDL (Mensink \& Katan, 1990; Nestel et al. 1992; Wood et al. 1993), reduced HDL (Mensink \& Katan, 1990) and elevated lipoprotein(a) (Lp(a)) (Nestel et al. 1992; Mensink et al. 1992) concentrations. High plasma $\mathrm{Lp}(\mathrm{a})$ concentration is known to be an independent risk factor for CHD and is normally resistant to dietary manipulation.

Sufficient evidence is emerging to indicate that compared to oleic acid, high intakes of elaidic acid represent a significant LDL raising factor. This may also be accompanied by significant increases in $\mathrm{Lp}$ (a) and, more controversially, decreased HDL cholesterol. Such evidence has led to calls for drastic cuts in the amount of trans fatty acid being consumed. What remains to be firmly established is the relative effects of elaidic acid and SFA. It would seem imprudent, at the present time, to recommend changes in dietary habits which exchange hydrogenated fats for those rich in lauric, myristic or palmitic acid. The effects of PUFA containing trans double bonds, at the relative low concentrations at which they occur, also remains to be established.

\section{n-3 POLYUNSATURATED FATTY ACIDS}

The $n-3$ PUFA represent a class of polyunsaturates in which the first double bond occurs after the third, rather than the more common sixth (n-6) carbon from the methyl end of the fatty acid. While these fatty acids are relatively rare in the tissues of animals they are more common in certain plant oils (e.g. linseed oil) and within the tissues of certain organisms of marine origin.

Much interest has focused on the potentially beneficial effect of fish oils, rich in eicosapentaenoic acid (C20:5) and docosahexaenoic acid (C22:6). This relates to findings that coastal populations, such as Greenland Eskimos, who habitually consume a diet rich in eicosapentaenoic acid and docosahexaenoic acid have an incidence of CHD as low as $8 \%$ of that of comparable inland populations (Kromann \& Green, 1980). This has led to 
numerous studies of the effects of diets enriched in oily fish or supplemented with fish oils. Harris (1989) reviewed the more well controlled studies performed up to that date. The overall effect on total and LDL cholesterol in normolipaemic subjects was judged to be negligible. A slight rise, of $3 \%$, in HDL cholesterol was calculated. Plasma TAG concentrations were much more dramatically affected with a $25 \%$ decrease. Thus, the overall conclusion of this analysis was that, while fish oils have a marked TAG lowering effect, there was little to suggest significant beneficial changes in total, LDL or HDL cholesterol concentrations. Thus, it is likely that any protective effects of fish oil consumption on cardiovascular risk relate to other risk factors such as platelet function, blood pressure, blood flow, inflammatory processes and the atherogenic process itself.

\section{REGULATION OF LOW DENSITY LIPOPROTEIN METABOLISM}

From the recent meta-analyses described above it is clear that much of the effect of dietary fatty acids on plasma cholesterol concentration is exerted on the LDL fraction. Thus SFA, with the exception of stearate, tend to increase LDL concentrations and MUFA and PUFA tend to decrease them. In recent years our understanding of the regulation of LDL metabolism and the control of expression of a number of genes involved in these pathways has increased dramatically. Before discussing potential mechanisms whereby dietary fatty acids may be influencing LDL metabolism, a brief summary of the regulation of certain key genes in the pathway is required.

LDL is produced by the action of lipolytic enzymes on very low density lipoprotein (VLDL) in the circulation. Thus, factors which influence the synthesis and secretion of VLDL may play an important role in regulating LDL production. VLDL comprises TAG, phospholipid, cholesterol, cholesterol ester and various apolipoproteins. Potentially the availability of any of these components may influence VLDL synthesis. Considerable evidence suggests that the availability of cholesterol is one important factor (Khan et al. 1989, 1990; Sessions et al. 1993). Cholesterol may be of dietary origin or synthesized de novo. Control of cholesterol synthesis de novo is exerted primarily through feedback inhibition, by sterols, of the enzymes HMG-CoA reductase and HMG-CoA synthase (EC 4.1.3.5) (reviewed by Goldstein \& Brown, 1990). Analysis of the promoter of the HMG-CoA reductase gene has identified a region bearing sequence homology with the sterol regulatory element (SRE-1) found in the LDL receptor (LDLR) gene (see below) but which is in the opposite orientation and differs by a single nucleotide (Osborne, 1991). When the intracellular sterol concentration is low, a specific sterol regulatory element binding protein (SREBP-1) binds to two adjacent sites within the SRE and activates transcription of the reductase gene (Vallett et al. 1996). A further low abundance protein, Red 25 (Osborne, 1991), also binds to the SRE but this appears to act as an inhibitor of transcription, binding only in the presence of sterol. Thus, the expression of the reductase gene may be tightly regulated by the opposing actions of these two proteins. It is possible that additional factors, different from those involved in the regulation of the LDLR gene, are required for the regulation of the HMG-CoA receptor gene. Further transcriptional control may well be exerted via cyclic AMP since the promoter region in both rat and hamster contains a sequence which is closely homologous to a consensus cAMP responsive element (Perillo et al. 1995). This has been shown to function in the regulation of HMGCoA reductase in rat thyroid cells.

Early work suggested that acute control of the enzyme itself may be exerted through a bicyclic phosphorylation-dephosphorylation system (Beg \& Brewer, 1982). Activation of phosphorylation via an AMP activated protein kinase by a reductase kinase inactivates HMG-CoA reductase while the reductase kinase is in turn inactivated by a second kinase 
(Ferrer et al. 1985). In this way, it was thought that hormones may exert a rapid effect on sterol synthesis by altering the degree of phosphorylation of the enzyme. However, there is increasing doubt as to the physiological relevance of this control since replacement of the serine residue which undergoes phosphorylation with alanine did not prevent the normal feedback inhibition of reductase activity of the mutant enzyme by mevalonate, 25hydroxycholesterol or LDL (Sato et al. 1994). Furthermore, acute changes in activity of the enzyme in diabetic rats treated with insulin and glucagon reflected changes in the levels of immunoreactive protein which in turn paralleled changes in HMG-CoA receptor mRNA (Ness et al. 1994a, b). Thus it appears that acute changes in HMG CoA receptor activity are also due to changes in the rate of gene transcription.

The major protein component of newly synthesized VLDL particles is apolipoprotein B (apoB). Studies in Hep-G2 cells concluded that apoB was constitutively expressed and that acute changes in the rates of apoB secretion were due to co- or post-translational processes (Pullinger et al. 1989). Similar conclusions were drawn from animal studies, e.g. rats (Davidson et al. 1988), mice (Srivastava et al. 1991), African green monkeys (Sorci-Thomas et al. 1989), suggesting that apoB gene transcription is not influenced by metabolic factors. However, evidence has been accumulating to suggest that pretranslational effects on apoB synthesis are also important. Thus, hepatic apoB mRNA levels may be modulated in vivo in both the rabbit (Kroon et al. 1986) and the rat (Matsumoto et al. 1987) by dietary cholesterol. Conclusive evidence that apoB mRNA levels exert control over synthesis and secretion of apoB-containing lipoproteins derive from experiments in transgenic rabbits and transfected cells. Overexpression of the human apoB gene in transgenic rabbits resulted in increased levels of LDL (Fan et al. 1995) while in a rat hepatoma cell line transfected with a recombinant human apoB gene, the rates of synthesis and secretion of apoBcontaining lipoproteins reflected the level of expression of the apoB gene in the cell line (Selby \& Yao, 1995).

ApoB, together with the various lipid components, must be incorporated into the VLDL particle. The microsomal TAG transfer protein (MTP) plays an essential role in the assembly of VLDL (Wetterau \& Gregg, 1995). The transport of the lipid moieties to the site of assembly is carried out by the larger $(88 \mathrm{kDa})$ subunit of MTP, a heterodimeric protein found in the lumen of the endoplasmic reticulum of both liver and intestine (Wetterau $e t$ al. 1991). The smaller $(58 \mathrm{kDa})$ subunit has been identified (Wetterau et al. 1990) as the multifunctional protein, protein disulphide isomerase (EC 5.3.4.1). The fact that patients with an absence of a functional MTP are unable to assemble or secrete apoB-containing lipoproteins (reviewed by Wetterau \& Gregg, 1995) suggests that control of MTP expression may regulate VLDL synthesis and secretion. The human and hamster MTP genes have been cloned (Lin et al. 1994) and functional analysis of the promoter region of the human MTP gene indicates the presence of a number of regulatory elements including a negative insulin response element and a modified sterol response element (Lin et al. 1995). Transient transfection of Hep-G2 cells with a luciferase gene attached to the MTP promoter indicated that both the elements are active in that insulin down-regulates and cholesterol up-regulates activity.

Once VLDL is secreted into the circulation it may undergo further modification with the transfer of apoproteins and lipids into and out of the particle. It has recently become clear that the transfer of cholesterol ester from the HDL fraction into VLDL and its remnants plays an important role in the 'reverse cholesterol transport pathway' (Fielding \& Fielding, 1995). Much of the TAG core of VLDL is then hydrolysed by lipoprotein lipase (EC 3.1.1.34). The major tissues involved in LPL synthesis are adipose tissue, muscle, especially cardiac muscle, and lactating mammary gland although enzyme expression is seen, albeit at lower levels, in brain, ovary, liver and macrophages (reviewed by Enerbäck 
\& Grimble, 1993). The enzyme is synthesized as a pre-pro-protein on the rough endoplasmic reticulum and undergoes intracellular transport and secretion, finally being transported to the luminal surface of the endothelium to which it is bound via proteoglycan. Thus, a number of potential regulatory sites exist for control of LPL activity and, in adipose tissue, LPL is regulated by both nutritional and physiological factors. Regulation can occur at the level of transcription as well as post-translationally. Multiple sites for transcriptional control, both positive and negative, exist on the promoter region of the gene including glucocorticoid receptor elements, fat specific element-2 and thyroid response elements (Lai et al. 1991).

Through the action of LPL, VLDL is converted into intermediate density lipoprotein (IDL). IDL is either directly removed from the circulation via interaction with LDLR in the liver, or further metabolized, probably by hepatic triglyceride lipase (EC 3.1.1.3), to produce $\mathrm{LDL}$. LDL is then removed from the circulation after interaction with the LDL (apoB, E) receptor or by receptor independent mechanisms. While virtually all tissues of the body make some contribution to LDL uptake, the liver is quantitatively the most important, accounting for $>60-80 \%$ of LDL turnover. This is predominantly by receptor dependent uptake (Dietschy et al. 1993). The LDLR also plays a major role in determining the rate of LDL production as it binds not only LDL itself but also IDL. Thus, when receptor expression is high, more particles are removed from the circulation as IDL and less LDL is formed. Conversely, if LDLR are down-regulated, in addition to reducing the rate of removal of LDL itself, fewer IDL particles are removed and hence more are converted to LDL. Transcription of the LDLR gene is regulated by cholesterol, and the cloning of the gene (Südhof et al. 1985) has enabled the mechanism of regulation to be investigated. One of the primary sites of regulation is a 10 base pair sequence in the $5^{\prime}$ flanking region designated the SRE-1 (see above) which is responsible for regulation by sterols, providing a binding site for SREBP. SRE-1 functions to enhance transcription only when the intracellular sterol concentration is low, and is inactivated when sterol accumulates. The mechanism by which sterols regulate LDLR gene expression via the SRE-1 has received much attention and two SREBP (SREBP-1 and SREBP-2) have been identified (Briggs et al. 1993; Wang et al. 1993). Native SREBP-1 is a $125 \mathrm{kDa}$ protein bound to endoplasmic reticulum and nuclear membranes (Wang et al. 1995). In the absence of sterols the protein is proteolytically cleaved to generate a $68 \mathrm{kDa}$ product which migrates to the nucleus and activates transcription of the LDLR gene via SRE-1. In the presence of sterols this proteolytic conversion from the $125 \mathrm{kDa}$ form to the $68 \mathrm{kDa}$ form is inhibited and any nuclear $68 \mathrm{kDa}$ protein is rapidly degraded with consequent inactivation of transcription. Two related SRE sequences which bind the transcription factor $\mathrm{Sp} 1$ are immediately adjacent to SRE-1 and may act synergically with SRE-1 to activate LDLR gene expression (Sanchez et al. 1995).

Non-sterol mediated regulation of LDLR transcription has also been demonstrated and may be tissue specific. For example, the $5^{\prime}$ flanking region of the LDLR gene contains a putative binding motif for Egr-1, a nuclear signal transducer induced by activation of tyrosine kinases and protein kinase C (Liu et al. 1993). Increased LDLR mRNA levels have also been shown in a leukaemic cell line treated with phorbol esters and a calcium ionophore again associated with protein kinase $\mathrm{C}$ and increased intracellular calcium (Makar et al. 1994). In both of these instances increased LDL gene expression was not prevented by increased intracellular sterol. The in vivo relevance of this, if any, is not known but it is possible that it may be involved in the normal regulation of LDLR gene expression.

Plasma LDL cholesterol concentrations are thus potentially dependent on the rate of VLDL production, the rate of lipolytic degradation of VLDL and its remnants, transfer of 


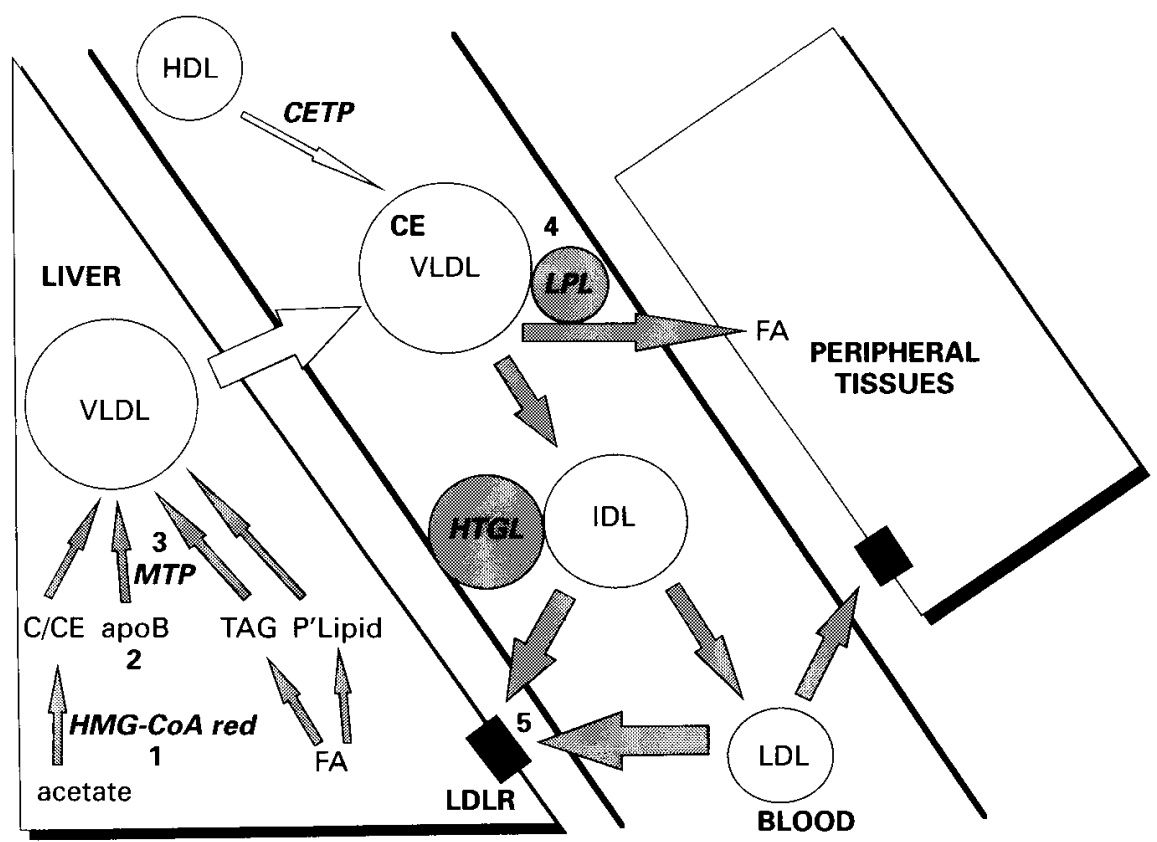

Fig. 1. Overview of low density lipoprotein metabolism. Fatty acids (FA) are incorporated into triacylglycerol (TAG) and phospholipid (P'Lipid) in the liver. Together with apolipoprotein (apo)B, cholesterol (C) and cholesterol ester (CE) they are incorporated into very low density lipoprotein (VLDL) particles. $\mathrm{C}$ and $\mathrm{CE}$ may be derived from exogenous sources or may be produced de novo in the liver. 3-Hydroxy-3-methylglutaryl coenzyme A reductase (HMG-CoA red) is a rate limiting enzyme in cholesterol biosynthesis. The microsomal triglyceride transfer protein (MTP) plays an important role in the incorporation of all of these lipids and apoB into the VLDL particle. VLDL is secreted into the circulation where it may undergo further modification including the addition of more CE donated by high density lipoprotein (HDL) through the action of the cholesterol ester transfer protein (CETP). Much of the TAG core of VLDL is hydrolysed by the action of lipoprotein lipase (LPL) which is anchored to the capillary endothelium in adipose tissue and muscle which take up much of the FA released. On loss of TAG and much of its surface components VLDL is released back into the circulation as intermediate density lipoprotein (IDL). IDL undergoes further modification probably by hepatic triglyceride lipase (HTGL) and is converted into cholesterol-rich, low density lipoprotein (LDL). Most of the LDL is removed from the circulation following uptake via the LDL receptor (LDLR) in the liver. Lesser amounts are also taken up after interaction with receptors in peripheral tissues. The regulation of expression of five of the proteins involved in this pathway: (1) HMG-CoA red, (2) apoB; (3) MTP; (4) LPL and (5) LDLR is discussed in the text.

cholesterol directly to the LDL particle and the rate of receptor-dependent and independent removal of IDL and LDL itself, primarily by the liver. An overview of these pathways is illustrated in Figure 1.

\section{MECHANISMS WHEREBY DIETARY FATTY ACIDS MAY INFLUENCE PLASMA LDL CONCENTRATIONS}

\section{FATTY ACID INCORPORATION INTO VLDL}

Fatty acids of both endogenous and exogenous origin can be incorporated into TAG and phospholipid destined for incorporation into VLDL. Different fatty acids appear to be specifically channelled into the synthesis of these lipids. For example, we have recently shown that relative to palmitic acid, stearic acid is poorly incorporated into hepatic TAG and preferentially directed towards phospholipid (Bruce \& Salter, 1996). The incorporation 


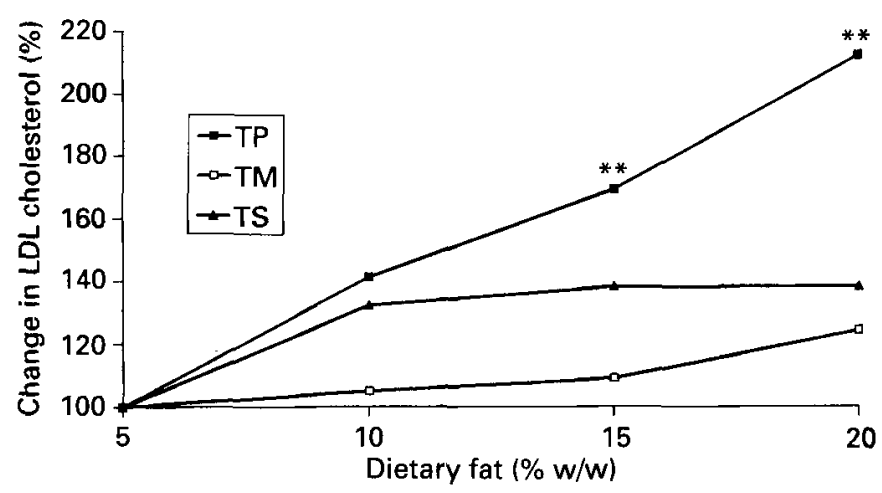

Fig. 2. Effect of different dietary saturated fats on plasma LDL concentrations in hamsters. Male Golden Syrian hamsters were fed semi-synthetic, isoenergetic diets containing $5,10,15$ or $20 \%$ fat (w/w), for $28 \mathrm{~d}$. Diets containing $5 \%$ fat contained triolein alone while the others consisted of half triolein and half trimyristin (TM), tripalmitin (TP) or tristearin (TS). LDL was isolated from plasma following an overnight fast. Results are presented as a percentage of the concentration found in animals fed the $5 \%$ fat diet. Significant differences from $5 \%$ fat diet: ${ }^{* *} P<0 \cdot 01$.

of TAG and cholesterol into VLDL appears to be coordinately regulated (Khan et al. 1989, 1990; Sessions et al. 1993). Thus, the metabolic fate of different fatty acids in the liver may influence their effect on VLDL secretion and ultimately LDL production.

\section{REGULATION OF HEPATIC STEROL METABOLISM}

Cholesterol, or one of its metabolites, can alter hepatic gene expression via the various SRE described above. It has been proposed that it is by altering the distribution of cholesterol between various pools within the liver that fatty acids exert many of their effects on cholesterol metabolism. Detailed studies by Woollett et al. $(1992 a, b)$ in which diets enriched in TAG containing fatty acids of defined chain length were fed to hamsters indicated that SFA of 12, 14 and 16 carbon atoms decrease LDLR activity and increase LDL production rate with a consequent increase in plasma LDL levels. In hamsters fed safflower oil or coconut oil the differences in LDL cholesterol were due primarily to altering receptor dependent uptake by the liver. Changes in LDL cholesterol paralleled changes in receptor protein and LDL receptor mRNA, suggesting that regulation of the LDLR pathway by fatty acids was largely at the level of mRNA (Horton et al. 1993). These effects were seen only in the presence of substantial amounts of cholesterol in the diet $(0 \cdot 12 \% \mathrm{w} / \mathrm{w})$. Such cholesterol feeding resulted in the accumulation of cholesterol ester in the liver. These workers suggest that it is by regulating the size of this cholesterol ester pool, and thereby the pool of sterol that regulates LDLR activity, that dietary fatty acids exert their effect (Spady et al. 1993). Thus, long chain SFA may decrease the storage of hepatic cholesterol ester, increase the size of the regulatory pool of cholesterol and down-regulate LDLR. By contrast oleic acid appears actively to increase the cholesterol ester pool, thereby decreasing the amount of 'regulatory cholesterol' and hence up-regulates LDLR expression. Finally, other fatty acids such as shorter chain SFA (C4-10), elaidic and linoleic acid appear to be essentially neutral in this process.

\section{DIETARY FATS AND GENE EXPRESSION}

The above mechanism may explain the effects of dietary fatty acids on LDL metabolism when sufficient dietary cholesterol is present to affect hepatic cholesterol ester concentrations, and the fatty acids may thus be modulating the effects of dietary cholesterol. 


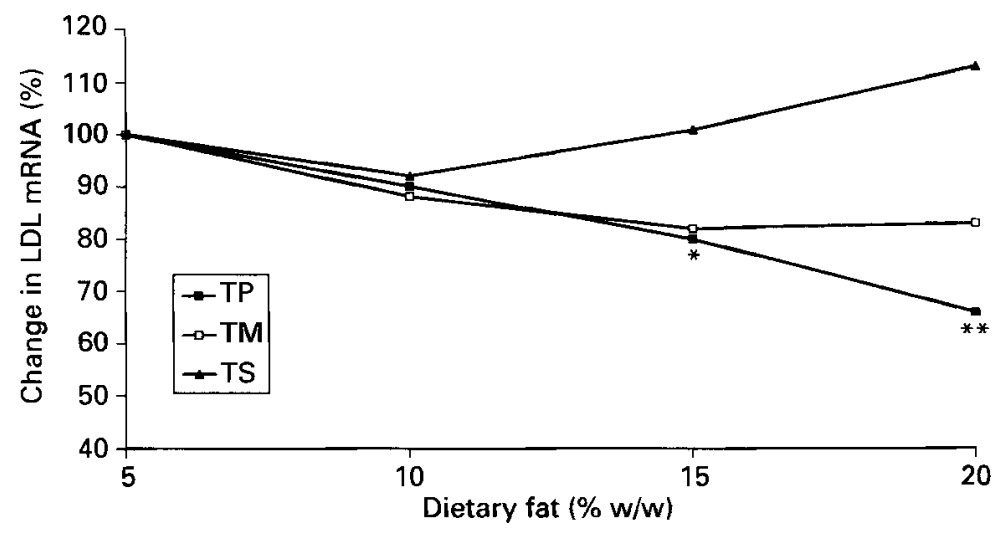

Fig. 3. Hepatic LDL receptor mRNA concentrations in hamsters fed different saturated fats. Animals were fed diets as indicated in Fig. 2. Hepatic LDL receptor mRNA was determined by nuclease protection assay as previously described (Bennett et al. 1995a). Results are presented as a percentage of the concentration found in animals fed the $5 \%$ fat diet. Significant differences from $5 \%$ fat diet: ${ }^{*} P<$ $0.05 ; * * P<0.01$.

However, similar reductions in hepatic LDLR mRNA with possible decreased synthesis of LDLR protein were found on feeding tripalmitin to hamsters on very low cholesterol diets $(0.005 \%)$, which did not result in the accumulation of hepatic cholesterol ester (Bennett et al. 1995a). More recent data from our laboratories indicate that in hamsters, palmitic acid but not myristic or stearic acids produce a dose dependent increase in plasma LDL cholesterol (Fig. 2) which is associated with a down-regulation of LDLR mRNA concentration (Fig. 3). Non-sterol mediated regulation of the LDLR gene has also been demonstrated in Hep-G2 cells (Ellsworth et al. 1991), human T cells (Makar et al. 1994) and fibroblasts (Roth et al. 1991). Furthermore, regulation of LDLR gene expression may occur post-transcriptionally, at least in Hep-G2 and $\mathrm{CaCo}-2$ cells. When these cells were incubated with palmitate a decrease in LDLR protein mass and activity occurred in the absence of any change in mRNA concentration (Srivastava et al. 1995). Changes in LDLR gene expression correlate closely with HMG-CoA reductase gene expression in a number of systems in vivo, e.g. mice (Rudling, 1992), hamster (Bennett et al. 1995a) and man (Powell \& Kroon, 1994), suggesting the coordinated regulation of the two genes.

Besides a decreased clearance of LDL via the LDLR, an increased plasma concentration of LDL cholesterol may also arise as a result of increased VLDL production rate, LDL being derived from VLDL. Thus, alterations in VLDL synthesis and secretion may influence the LDL cholesterol concentration. From studies on cells in culture it was thought that regulation of apoB gene expression was post-translational (Pullinger et al. 1989; Dixon \& Ginsberg, 1993), and this may be true acutely. However, hepatic apoB mRNA levels were altered on chronic feeding of specific dietary fats and cholesterol in the rabbit (Kroon et al. 1986) and rat (Matsumoto et al. (1987) and the decreased secretion of apoB by CaCo2 cells incubated with eicosapentaenoic acid was ascribed to a decrease in the level of apoB mRNA in the cells (Murthy et al. 1992). Dietary fatty acids may also have differential effects on apoB gene expression. Hepatic apoB mRNA levels were raised in cebus monkeys fed a coconut oil diet compared to those fed a corn oil diet (Hennessy et al. 1992) and, in a study to investigate the action of specific dietary fatty acids, presented as TAG, on hepatic gene expression in hamsters, palmitate, but not myristate, oleate or stearate, increased the levels of apoB mRNA (Bennett et al. 1995a). Although the amount of secreted apoB protein was not measured in this latter case, increased levels of apoB mRNA in Hep-G2 

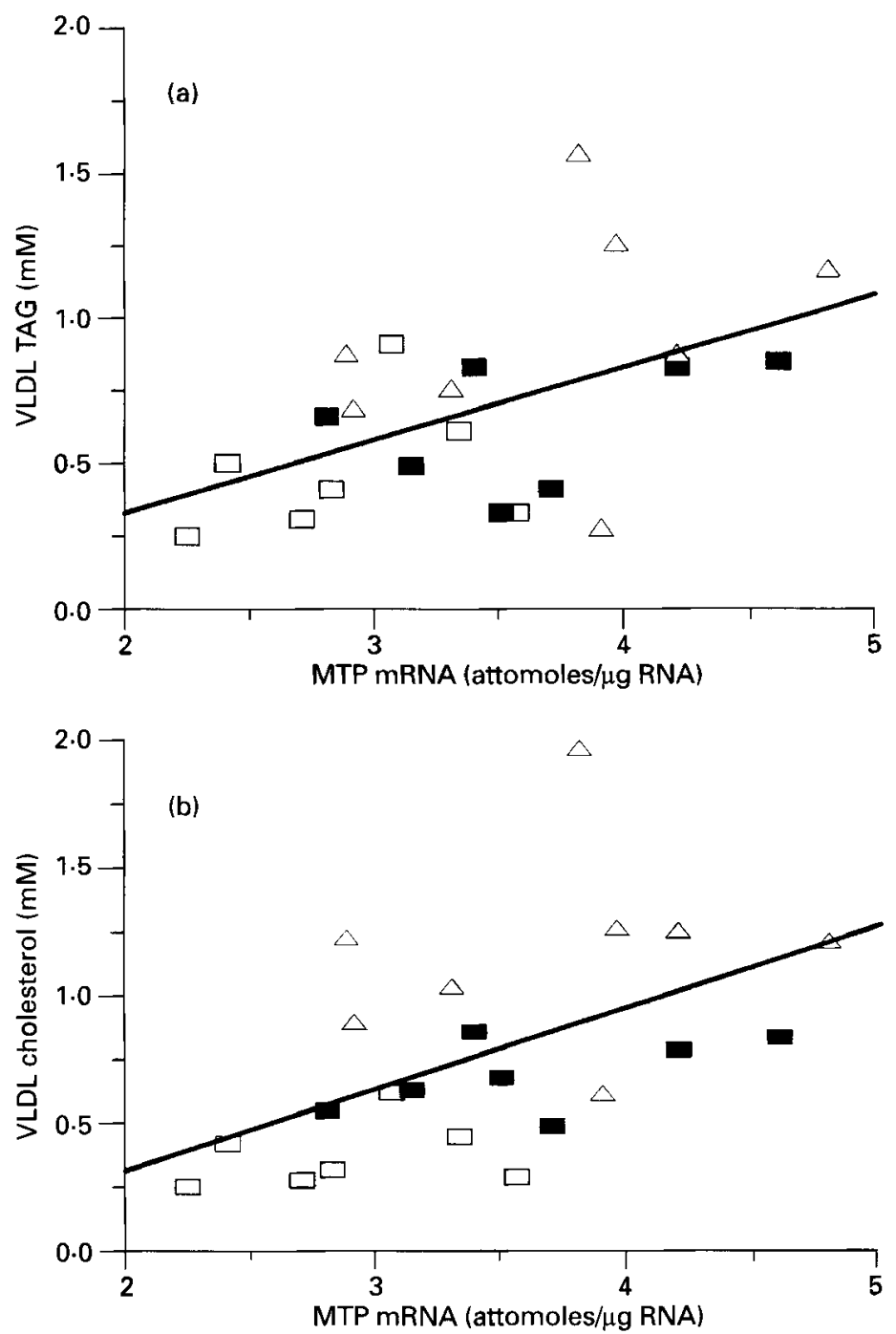

Fig. 4. Correlation between microsomal TAG transfer protein (MTP) mRNA concentrations and (a) VLDL triacylglycerol (TAG) and (b) VLDL cholesterol in cholesterol fed hamsters. Male Golden Syrian hamsters were fed semi-synthetic diets containing $20 \%(\mathrm{w} / \mathrm{w})$ fat, which consisted of half triolein and half tristearin. This diet was supplemented with $0.005(\square), 0.12(\square)$ or $0.24 \%(\triangle)$ cholesterol $(\mathrm{w} / \mathrm{w})$. Both VLDL TAG and cholesterol increased as the amount of cholesterol in the diet increased and both were correlated with hepatic MTP mRNA concentrations $(r=0.51, P<0.05$ and $r=0.49, P<0.05$ respectively).

cells brought about by incubation with 25-hydroxycholesterol (Dashti, 1992), low concentrations of amino acids (Zhang et al. 1993) or VLDL (Wu et al. 1994), were associated with increased secretion of apoB-containing lipoproteins.

The expression of MTP is also susceptible to regulation by dietary factors. In hamsters fed high fat, stearate enriched diets, increased dietary cholesterol was associated with increases in hepatic MTP mRNA concentrations and plasma VLDL lipid concentrations (Fig. 4). This suggests that increases in VLDL might be mediated at least in part through increased MTP gene expression (Fig. 4). Feeding a high fat diet 
(control chow supplemented with $20 \%$ hydrogenated coconut oil) to hamsters for $31 \mathrm{~d}$ caused marked increases in MTP large subunit mRNA levels in both liver and intestine (Lin et al. 1994). The increase in hepatic MTP mRNA in response to dietary fat in hamsters was dose dependent and correlated with VLDL, LDL and HDL cholesterol concentrations but not VLDL TAG (Bennett et al. 1995b). Furthermore, the nature of the dietary fat appeared important for the regulation of gene expression. Both palmitate and myristate but not stearate raise hepatic MTP mRNA concentrations significantly above that of oleate and linoleate fed animals (Bennett et al. 1995b).

Finally, it has become clear recently that fatty acids can also regulate both the expression and activity of the LPL gene and thus potentially the rate of conversion of VLDL to LDL. In adipose cells in culture, free fatty acids increase LPL gene expression yet decrease LPL activity under conditions where LPL protein content remains relatively constant (Amri et al. 1996). That this is a direct effect of intact fatty acids rather than some indirect action is indicated by the use of a non-metabolized fatty acid analogue, 2-bromopalmitate. It was suggested that in adipose cells transcriptional control was most likely to occur by the transacting factor fatty acid activated receptor which by forming a dimer with the retinoic acid receptor recognizes a putative peroxisome proliferator response element in the LPL promoter. Evidence was also produced to suggest that free fatty acids regulate the posttranslational processing of LPL. There may also be an effect on LPL mRNA stability through interaction of the three-prime untranslated region with specific proteins.

\section{CONCLUSIONS}

Early work firmly established a link between the quantity and quality of dietary fat and plasma cholesterol concentrations. Most dietary recommendations are still based on the outcome of such studies. More recent evidence has suggested specific and unique effects of individual fatty acids on plasma cholesterol and its distribution between the individual lipoprotein classes. Meta-analyses have quantified these effects in such a way that the influence of a particular dietary fat can be predicted from its fatty acid profile. A major challenge for the future is to be able to translate this information into specific, LDL cholesterol lowering dietary recommendations. It seems unlikely that the interpretation of such data can be left in the hands of the consumer and it may be put to greater use by the oils and fats industry in formulating products.

Major advances have been made in recent years in our understanding of the molecular mechanisms whereby dietary fatty acids influence lipoprotein metabolism. It has become quite clear that in addition to their well defined roles in energy metabolism, as constituents of membranes and as precursors of hormones, fatty acids might also directly regulate gene expression. It appears likely that future research will provide a greater understanding of the mechanisms whereby fatty acids exert many of their regulatory effects on lipoprotein metabolism.

The authors would like to thank our colleagues at the University of Nottingham: Dr A. J. Bennett, Dr M. A. Billett, Ms J. S. Bruce, Dr E. H. Mangiapane and Dr V. A. Sessions for their contributions to the work described in this review and their help in its preparation. The work was funded by the Ministry of Agriculture, Fisheries \& Food, Contract no. CSA 2047.

\section{REFERENCES}

Amri, E., Teboul, L., Vannier, C., Grimaldi, P.-A. \& Ailhaud, G. (1996). Fatty acids regulate the expression of lipoprotein lipase gene and activity in preadipose and adipose cells. Biochemical Journal 314, 541-546. 
Ascherio, A., Hennekens, C. H., Buring, J. E., Master, C., Stampfer, M. J. \& Willett, W. C. (1994). Trans-fatty acids intake and risk of myocardial infarction. Circulation 89,94-101.

Beg, Z. H. \& Brewer, H. B. (1982). Modulation of rat liver 3-hydroxy-3-methylglutaryl coenzyme A reductase activity by reversible phosphorylation. Federation Proceedings 41, 2634-2638.

Bennett, A. J., Billett, M. A., Salter, A. M., Mangiapane, E. H., Bruce, J. S., Anderton, K. L., Marenah, C. B., Lawson, N. \& White, D. A. (1995a). Modulation of hepatic apolipoprotein B, 3-hydroxy-3-methylglutarylCOA reductase and low density lipoprotein receptor mRNA and plasma lipoprotein concentrations by defined dietary fats. Comparison of trimyristin, tripalmitin, tristearin and triolein. Biochemical Journal 311, 167-173.

Bennett, A. J., Billett, M. A., Salter, A. M., \& White, D. A. (1995b). Regulation of hamster hepatic microsomal triglyceride transfer protein mRNA levels by dietary fats. Biochemical and Biophysical Research Communications 212, 473-478.

Briggs, M. R., Yokoyama, C., Wang, X., Brown, M. S. \& Goldstein, J. L. (1993). Nuclear protein that binds sterol regulatory element of low density lipoprotein receptor promoter. 1. Identification of the protein and delineation of its target nucleotide sequence. Journal of Biological Chemistry 268, 14490-14496.

Bruce, J. S. \& Salter, A. M. (1996). Metabolic fate of oleic acid, palmitic acid and stearic acid in cultured hamster hepatocytes. Biochemical Journal 316, 847-852.

Dashti, N. (1992). The effect of low density lipoproteins, cholesterol, and 25-hydroxycholesterol on apolipoprotein B gene expression in Hep G2 cells. Journal of Biological Chemistry 267, 7160-7169.

Davidson, N. O., Drewek, M. J., Gordon, J. 1. \& Elovson, J. (1988). Rat intestinal apolipoprotein B gene expression. Evidence for integrated regulation by bile salt, fatty acid, and phospholipid flux. Journal of Clinical Investigation 82, 300-308.

Derr, J., Kris-Etherton, P. M., Pearson, T. A. \& Seligson, F. H. (1993). The role of fatty acid saturation on plasma lipids, lipoproteins, and apolipoproteins. II. The plasma total and low-density lipoprotein cholesterol response to individual fatty acids. Metabolism 42,130-134

Dietschy, J. M., Turley, S. D. \& Spady, D. K. (1993). Role of liver in the maintenance of cholesterol and low density lipoprotein homeostasis in different animal species, including humans. Journal of Lipid Research 34, $1637-1659$.

Dixon, J. L. \& Ginsberg, H. N. (1993). Regulation of hepatic secretion of apolipoprotein B-containing lipoproteins: information obtained from cultured liver cells. Journal of Lipid Research 34, 167-179.

Ellsworth, J, L., Chandrasekaran, C. \& Cooper, A. D. (1991). Evidence for sterol-independent regulation of lowdensity lipoprotein receptor activity in Hep-G2 cells. Biochemical Journal 279, 175-187.

Enerbäck, S. \& Grimble, J. M. (1993). Lipoprotein lipase gene expression: physiological regulators at the transcriptional and post-transcriptional level. Biochimica et Biophysica Acta 1169, 107-125.

Fan, J, McCormick, S. P. A., Krauss, R. M., Taylor, S., Quan, R., Taylor, J. M. \& Young, S. G. (1995). Overexpression of human apolipoprotein B-100 in transgenic rabbits results in increased levels of LDL and decreased levels of HDL. Arteriosclerosis, Thrombosis, and Vascular Biology 15, 1889-1899.

Ferrer, A., Caelles, C., Massot, N. \& Hegardt, F. G. (1985). Activation of rat liver cytosolic 3-hydroxy-3methylglutaryl coenzyme A reductase kinase by adenosine 5'-monophosphate. Biochemical and Biophysical Research Communications 132, 497-504.

Fielding, C. J. \& Fielding, P. E. (1995). Molecular physiology of reverse cholesterol transport. Journal of Lipid Research 36, 211-228.

Gardner, C. D. \& Kraemer, H. C. (1995). Monounsaturated versus polyunsaturated dietary fat and serum lipids. A meta-analysis. Arteriosclerosis, Thrombosis, \& Vascular Biology 15, 1917-1927.

Gibbons, G. F. \& Wiggins, D. (1995). The enzymology of hepatic very-low-density lipoprotein assembly. Biochemical Society Transactions 23, 495-500.

Goldstein, J. L. \& Brown, M. S. (1990). Regulation of the mevalonate pathway. Nature 343, 425-430.

Harris, W. S. (1989). Fish oils and plasma lipid and lipoprotein metabolism in humans: a critical review. Journal of Lipid Research 30, 785-807.

Hayes, K. C. \& Khosla, P. (1992). Dietary fatty acid thresholds and cholesterolemia. FASEB Journal 6, $2600-2607$.

Hayes, K. C., Pronczuk, A. \& Khosla, P. (1995). A rationale for plasma cholesterol modulation by dietary fatty acids: modeling the human response in animals. Journal of Nutritional Biochemistry 6, 188-194.

Hayes, K. C., Pronczuk, A., Lindsey, S. \& Diersen-Schade, D. (1991). Dietary saturated fatty acids (12:0, 14:0, 16:0) differ in their impact on plasma cholesterol and lipoproteins in non-human primates. American Journal of Clinical Nutrition 53, 491-498.

Hegsted, D. M., Ausman, L. M., Johnson, J. A. \& Dallal, G. E. (1993). Dietary fat and serum lipids: an evaluation of the experimental data. American Journal of Clinical Nutrition 57, 875-883.

Hegsted, D. M., McGandy, R. B., Myers, M. L. \& Stare, F. J. (1965). Quantitative effects of dietary fat on serum cholesterol in man. American Journal of Clinical Nutrition 17, 281-295.

Hennessy, L. K., Osada, J., Ordovas, J. M., Nicolosi, R. J., Stucchi, A. F., Brousseau, M. E. \& Schaefer, E. J. (1992). Effects of dietary fats and cholesterol on liver lipid content and hepatic apolipoprotein A-1, B, and E and LDL receptor mRNA levels in cebus monkeys. Journal of Lipid Research 33, 351-360.

Horton, J. D., Cuthbert, J. A. \& Spady, D. K. (1993). Dietary fatty acids regulate hepatic low density lipoprotein (LDL) transport by altering LDL receptor protein and mRNA levels. Journal of Clinical Investigation 92, 743-749. 
Keys, A., Anderson, J. T. \& Grande, F. (1965). Serum cholesterol response to changes in the diet. IV. Particular saturated fatty acids in the diet. Metabolism 14, 776-787.

Khan, B. V., Fungwe, T. V., Wilcox, H. G. \& Heimberg, M. (1990). Cholesterol is required for the secretion of the very-low-density lipoprotein: in vivo studies. Biochimica et Biophysica Acta 1044, 297-304.

Khan, B., Wilcox, H. G. \& Heimberg, M. (1989). Cholesterol is required for secretion of very-low-density lipoprotein by rat liver. Biochemical Journal 258, 807-816.

Khosla, P. \& Hayes, K. C. (1993). Dietary palmitic acid raises plasma LDL cholesterol relative to oleic acid only at a high intake of cholesterol. Biochimica et Biophysica Acta 1210, 13-22.

Kromann, N. \& Green, A. (1980). Epidemiological studies in the Upernavik district, Greenland. Incidence of some chronic diseases 1950-1974. Acta Medica Scandinavica 208: 401-406.

Kroon, P. A., DeMartino, J. A., Thompson, G. M. \& Chao, Y.-S. (1986). Molecular cloning of partial cDNAs for rabbit liver apolipoprotein $\mathrm{B}$ and the regulation of its mRNA levels by dietary cholesterol. Proceedings of the National Academy of Sciences, USA 83, 5071-5075.

Lai, E., Prezioso, V. R., Tao, W. F., Chen, W. S. \& Darnell, J. E. (1991). Hepatocyte nuclear factor $3 \alpha$ belongs to a gene family in mammals that is homologous to the Drosophila homeotic gene fork-head. Genes and Development 5, 416-427.

Lin, M. C. M., Arbeeny, C., Bergquist, K., Kienzle, B., Gordon, D. A. \& Wetterau, J. R. (1994). Cloning and regulation of hamster microsomal triglyceride transfer protein. The regulation is independent from that of other hepatic and intestinal proteins which participate in the transport of fatty acids and triglycerides. Journal of Biological Chemistry 269, 29138-29145.

Lin, M. C. M., Gordon, D. \& Wetterau, J. R. (1995). Microsomal triglyceride transfer protein (MTP) regulation in HepG2 cells: insulin negatively regulates MTP gene expression. Journal of Lipid Research 36, $1073-1081$.

Liu, J. W., Shoyab, M. \& Grove, R. I. (1993). Induction of Egr-1 by oncostatin M precedes up-regulation of low density lipoprotein receptors in Hep G2 cells. Cell Growth and Differentiation 4, 611-616.

Makar, R. S. J., Lipsky, P. E. \& Cuthbert, J. A. (1994). Nonsterol regulation of low density lipoprotein receptor gene expression in T cells. Journal of Lipid Research 35, 1888-1895.

Matsumoto, A., Aburatani, H., Shibasaki, Y., Kodama, T., Takaku, F. \& Itakura, H. (1987). Cloning and regulation of rat apolipoprotein B mRNA. Biochemical and Biophysical Research Communications $142,92-99$.

Mattson, F. H. \& Grundy, S. M. (1985). Comparison of effects of dietary saturated, monounsaturated, and polyunsaturated fatty acids on plasma lipids and lipoproteins in man. Journal of Lipid Research 26, 194202.

Mensink, R. P., \& Katan, M. B. (1990). Effects of dietary trans fatty acids on high density and low density lipoprotein cholesterol levels in healthy subjects. New England Journal of Medicine 323, 439-445.

Mensink, R. P. \& Katan, M. B. (1992). Effects of dietary fatty acids on serum lipids and lipoproteins. A metaanalysis of 27 trials. Arteriosclerosis \& Thrombosis 12, 911-919.

Mensink, R. P., Zock, P. L., Katan, M. B. \& Hornstra, G. (1992). Effect of dietary cis and trans fatty acids on serum lipoprotein[a] levels in humans. Journal of Lipid Research 33, 1493-1501.

Multiple Risk Factor Intervention Trial Research Group (1982). Multiple risk factor intervention trials. Risk factor mortality results. Journal of the American Medical Association 248, 1465-1477.

Murthy, S., Albright, E., Mathur, S. N., Davidson, N. O. \& Field, F. J. (1992). Apolipoprotein B mRNA abundance is decreased by eicosapentaenoic acid in $\mathrm{CaCo}-2$ cells. Effect on the synthesis and secretion of apolipoprotein B. Arteriosclerosis and Thrombosis 12, 691-700.

Ness, G. C., Eales, S., Lopez, D. \& Zhao, Z. (1994a). Regulation of 3-hydroxy-3-methylglutaryl coenzyme A reductase gene expression by sterols and nonsterols in rat liver. Archives of Biochemistry and Biophysics $\mathbf{3 0 8}$, $420-425$

Ness, G. C., Zhao, Z. \& Wiggins, L. (1994 b). Insulin and glucagon modulate hepatic 3-hydroxy-3-methylglutaryl coenzyme A reductase activity by affecting immunoreactive protein levels. Journal of Biological Chemistry 269 , 29168-29172.

Nestel, P., Noakes, M., Belling, B., McArthur, R., Clifton, P., Janus, E. \& Abbey, M. (1992). Plasma lipoprotein lipid and $\mathrm{Lp}[\mathrm{a}]$ changes with substitution of elaidic acid for oleic acid in the diet. Journal of Lipid Research 33, 1029-1036.

Oliver, M.F. (1991). Might treatment of hypercholesterolaemia increase non-cardiac mortality? Lancet 337, $1529-1531$

Osborne, T. F. (1991). Single nucleotide resolution of sterol regulatory region in promoter for 3-hydroxy-3methylglutaryl coenzyme A reductase. Journal of Biological Chemistry 266, 13947-13951.

Perillo, B., Tedesco, I., Laezza, C., Santillo, M., Romano, A., Aloj, S. M. \& Bifulco, M. (1995). Regulation of 3hydroxy-3-methylglutaryl coenzyme A reductase gene expression in FRTL-5 cells. 2. Down-regulation by v-Kras oncogene. Journal of Biological Chemistry 270, 15237-15241.

Powell, E. E. \& Kroon, P. A. (1994). Low density lipoprotein receptor and 3-hydroxy-3-methylglutaryl coenzyme A reductase gene expression in human mononuclear leukocytes is regulated coordinately and parallels gene expression in human liver. Journal of Clinical Investigation 93, 2168-2174.

Pufal, D. A., Quinlan, P. T. \& Salter, A. M. (1995). Effect of dietary triacylglycerol structure on lipoprotein metabolism: a comparison of the effects of dioleoylpalmitoylglycerol in which palmitate is esterified to the 2or 1(3)-position of the glycerol. Biochimica et Biophysica Acta 1258, 41-48.

Pullinger, C. R., North, J. D., Yeng, B.-B., Rifici, V. A., Ronhild de Brito, A. E. \& Scott, J. (1989). The 
apolipoprotein B gene is constitutively expressed in Hep G2 cells: regulation of secretion by oleic acid, albumin, and insulin, and measurement of the mRNA half-life. Journal of Lipid Research 30, 1065-1077.

Roth, M., Emmons, L. R., Perruchoud, A. \& Block, L. H. (1991). Expressions of the low density lipoprotein receptor and 3-hydroxy-3-methylglutaryl coenzyme $\mathrm{A}$ reductase genes are stimulated by recombinant plateletderived growth factor isomers. Proceedings of the National Academy of Science, USA 88, 1888-1892.

Rudling, M. (1992). Hepatic mRNA levels for the LDL receptor and HMG-CoA reductase show coordinate regulation in vivo. Journal of Lipid Research 33, 493-501.

Sanchez, H. B., Yieh, L. \& Osborne, T. F. (1995). Cooperation by sterol regulatory element-binding protein and $\mathrm{Spl}$ in sterol regulation of low density lipoprotein receptor gene. Journal of Biological Chemistry 270, 1161-1169.

Sato, R., Yang, J., Wang, X., Evans, M. J., Ho, Y. K., Goldstein, J. L. \& Brown, M. S. (1994). Assignment of the membrane attachment, DNA binding and transcriptional activation domains of sterol regulatory elementbinding protein-1 (SREBP-1). Journal of Biological Chemistry 269, 17267-17273.

Selby, S. L. \& Yao, Z. (1995). Level of apolipoprotein B mRNA has an important effect on the synthesis and secretion of apolipoprotein B-containing lipoproteins. Studies on transfected hepatoma cell lines suppressing recombinant human apolipoprotein B. Arteriosclerosis, Thrombosis, and Vascular Biology 15, 1900-1910.

Sessions, V. A., Martin, A., Gomez-Muñoz, A., Brindley, D. N. \& Salter, A. M. (1993). Cholesterol feeding induces hypertriglyceridaemia in hamsters and increases the activity of $\mathrm{Mg}^{2+}$-dependent phosphatidate phosphohydrolase in the liver. Biochimica et Biophysica Acta 1166, 238-243.

Shepherd, J., Cobbe, S. M., Ford, I., Isles, C. G., Lorimer, A. R., MacFarlane, P. W., McKillop, J. H. \& Packard, C. J. (1995). Prevention of coronary heart disease with pravastatin in men with hypercholesterolemia. New England Journal of Medicine 333: 1301-1307.

Small, D. M. (1991). The effects of glyceride structure on absorption and metabolism. Annual R view of Nutrition $11,413-434$.

Sorci-Thomas, M., Wilson, M. D., Johnson, F. L., Williams, D. L. \& Rudel, L. L. (198\&). Studies on the expression of genes encoding apolipoproteins B-100 and B-48 and the low density lipoprotein receptor in non human primates. Comparison of dietary fat and cholesterol. Journal of Biological Chemistry 264, 9039-9045.

Spady, D. K., Woollett, L. A. \& Dietschy, J. M. (1993). Regulation of plasma LDL-cholesterol levels by dietary cholesterol and fatty acids. Annual Review of Nutrition 13, 355-381.

Srivastava, R. A. K., Ito, H., Hess, M., Srivastava, N. \& Schonfeld, G. (1995). Regulation of low density lipoprotein receptor gene expression in Hep G2 and Caco-2 cells by palmitate, oleate, and 25hydroxycholesterol. Journal of Lipid Research 36, 1434-1446.

Srivastava, R. A. K., Jiao, S., Tang, J. J., Pfleger, B. A., Kitchens, R. T. \& Schonfeld, G. (1991). In vivo regulation of low density lipoprotein receptor and apolipoprotein $B$ gene expressions by dietary fat and cholesterol in inbred strains of mice. Biochimica et Biophysica Acta 1086, 29-43.

Südhof, T. C., Goldstein, J. L.,Brown, M. S. \& Russell, D. W. (1985). The LDL receptor gene : a mosaic of exons shared with different proteins. Science 228, 815-822.

Sundram, K., Hayes, K. C. \& Siru, O. H. (1994). Dietary palmitic acid results in lower serum cholesterol than does a lauric-myristic acid combination in normolipemic humans. American Journal of Clinical Nutrition 59, 841-846.

Sundram, K., Hayes, K. C. \& Siru, O. H. (1995). Both dietary 18:2 and 16:0 may be required to improve the serum LDL/HDL cholesterol ratio in normocholesterolemic men. Journal of Nutritional Biochemistry 6 , 179-187.

Tholstrup, T., Marckmann, P., Jespersen, J., Vessby, B., Jart, A. \& Sandström, B. (1994). Effect on blood lipids, coagulation, and fibrinolysis of a fat high in myristic acid and a fat high in palmitic acid. American Journal of Clinical Nutrition 60, 919-925.

Valett, S. M., Sanchez, H. B., Rosenfeld, J. M. \& Osborne, T. F. (1996). A direct role of sterol regulatory element binding protein in activation of 3-hydroxy-3-methylglutaryl coenzyme A reductase gene. Journal of Biological Chemistry 271, 12247-12253.

Wang, X., Briggs, M. R., Hua, X., Yokoyama, C., Goldstein, J. L. \& Brown, M. S. (1993). Nuclear protein that binds sterol regulatory element of low density lipoprotein receptor promoter. 2. Purfication and characterization. Journal of Biological Chemistry 268, 14497-14504.

Wang, X., Pai, J.-T., Wiedenfeld, E. A., Medina, J. C., Slaughter, C. A., Goldstein, J. L. \& Brown, M. S. (1995). Purification of an interleukin- $1 \beta$ converting enzyme-related cysteine protease that cleaves sterol regulatory element-binding proteins between the leucine zipper and transmembrane domains. Journal of Biological Chemistry 270, $18044-18050$.

Wetterau, J. R., Aggerbeck, L. P., Laplaud, P. M. \& McLean, L. R. (1991). Structural properties of the microsomal triglyceride-transfer protein complex. Biochemistry 30, 4406-4412.

Wetterau, J. R., Combs, K. A., Spinner, S. N. \& Joiner, B. J. (1990). Protein disulfide isomerase is a component of the microsomal triglyceride transfer protein complex. Journal of Biological Chemistry 265, $9800-9807$.

Wetterau, J. R. \& Gregg, R. E. (1995). Microsomal triglyceride transfer protein: insights into lipoprotein assembly and abetalipoproteinaemia. In Atherosclerosis $X$, pp. 40-44 [F. P. Woodford, J. Davignon and A. Sniderman, editors]. Amsterdam: Elsevier Science B.V.

Willett, W. C., Stampfer, M. J., Manson, J. E., Colditz, G. A., Speizer, F. E., Rosner, B. A., Sampson, L. A. \& Hennekens, C. H. (1993). Intake of trans fatty acids and risk of coronary heart disease among women. Lancet 341, 581-585. 
Wood, R., Kubena, K., O’Brien, B., Tseng, S. \& Martin, G. (1993). Effect of butter, mono-and polyunsaturated fatty acid-enriched butter, trans fatty acid margarine, and zero trans fatty acid margarine on serum lipids and lipoproteins in healthy men. Journal of Lipid Research 34, 1-11.

Woollett, L. A., Spady, D. K. \& Dietschy, J. M. (1992a). Regulatory effects of the saturated fatty acids 6:0 through 18:0 on hepatic low density lipoprotein receptor activity in the hamster. Journal of Clinical Investigation 89, $1133-1141$.

Woollett, L. A., Spady, D. K. \& Dietschy, J. M. (1992b). Saturated and unsaturated fatty acids independently regulate low density lipoprotein receptor activity and production rate. Journal of Lipid Research 33, $77-88$.

Wu, X., Sakata, N., Dixon, J. \& Ginsberg, H. N. (1994). Exogenous VLDL stimulates apolipoprotein B secretion from Hep G2 cells by both pre- and post-translational mechanisms. Journal of Lipid Research 35, 1200-1210.

Yu, S. M., Derr, J., Etherton, T. D. \& Kris-Etherton, P. M. (1995). Plasma cholesterol-predictive equations demonstrate that stearic acid is neutral and monounsaturated fatty acids are hypocholesterolemic. American Journal of Clinical Nutrition 61, 1129-1139.

Zhang, Z. J., Sniderman, A. D., Kalant, D., Vu, H., Monge, J. C., Tao, T. Z. \& Cianflone, K. (1993). The role of amino acids in apoB 100 synthesis and catabolism in human HepG2 cells. Journal of Biological Chemistry 268, $26920-26926$.

Zock, P. L., de Vries, J. H. M. \& Katan, M. B. (1994). Impact of myristic acid versus palmitic acid on serum lipid and lipoprotein levels in healthy women and men. Arteriosclerosis \& Thrombosis 14, 567-575.

Zock, P. L., de Vries, J. H. M., de Fouw, N. J. \& Katan, M. J. (1995). Positional distribution of fatty acids in dietary triglycerides: effects on fasting blood lipoprotein concentrations in humans. American Journal of Clinical Nutrition 61, 48-55. 